\title{
Rancang Bangun Pemanas Air Surya Tipe Datar
}

\author{
Rinjani Rakasiwi ${ }^{1)}$, Syaifurrahman ${ }^{2}$, dan Usman A Gani ${ }^{3)}$ \\ ${ }^{1)}$ Prodi Teknik Kimia, Fakultas Teknik, Universitas Tanjungpura \\ ${ }^{2,3)}$ Jurusan Teknik Elektro, Fakultas Teknik, Universitas Tanjungpura \\ email: ${ }^{1)}$ rinjani_s@yahoo.com, ${ }^{2)}$ syaifur.rahman@yahoo.com, ${ }^{3)}$ usmanagani@gmail.com
}

\begin{abstract}
Abstrak- Kalimantan Barat dilalui Garis Khatulistiwa dimana surya menyinari selama 10-15 jam/hari. Energi surya diserap langsung oleh sistem pemanas surya. Energi panas yang dihasilkan dapat digunakan sebagai sumber panas dalam menghasilkan bahan bakar terbarukan misalnya bioetanol dan biodiesel. Implementasi untuk gagasan di atas dapat berupa teknologi pemanas surya yang sederhana, tanpa memerlukan energi listrik, biaya operasi murah dan ramah lingkungan. Tujuan penelitian ini adalah merancang dan menguji pemanas air surya. Pemanas surya dirancang bertipe datar dengan media pemanas berupa air. Pemanas surya terdiri dari kolektor panas dan tangki penampung air yang terbuat dari bahan stainlees steel dan polistiren sebagai isolator. Hasil rancang diperoleh pemanas air surya berkapasitas 50 liter yang diuji selama 3 hari dan mampu menghasilkan temperatur air maksimal sebesar $53^{\circ} \mathrm{C}$ pada intensitas cahaya rata-rata sebesar 1426 lux.
\end{abstract}

Kata Kunci: Energi terbarukan, intensita cahaya, khatulistiwa, pemanas, surya

\section{Pendahuluan}

Sumber energi terbarukan yaitu energi surya dihasilkan oleh proses peleburan nuklir oleh hidrogen menjadi helium dan menghasilkan laju massa pengosongan sebesar $4,7 \times 10^{6}$ ton/s [1]. Dewasa ini panas surya telah diaplikasikan sebagai sumber energi untuk mesin pembangkit, mesin pendingin, alat penukar panas, dan sistem air panas di perkotaan. Berdasarkan data Ditjen Listrik dan Pengembangan Energi, kapasitas terpasang listrik tenaga surya di Indonesia baru mencapai $0,88 \mathrm{MW}$ dari potensi yang tersedia sebesar $1,1 \times 10^{9}$ MW [2]. Pemanfaatan energi panas surya diaplikasikan dengan teknologi pemanas air surya yang menggunakan medium pemanas berupa fluida air [3].

Pemanas air surya dapat digolongkan menjadi 2 jenis yaitu pemanas pasif dan pemanas aktif. Pemanas pasif murni mengandalkan panas matahari dan tidak menggunakan listrik. Sedangkan pemanas aktif memanfaatkan pompa dan sistem control tenaga listrik serta dilengkapi dengan emergency back-up. Pemanas air surya pasif memiliki 2 bagian, yaitu panel kolektor dan tangki penyimpan air yang saling terhubung dengan dua pipa. Pada panel kolektor yang ditutup oleh kaca, didalamnya terdapat serangkaian pipa tembaga sebagai jalannya air dengan sirip-sirip sebagai penyerap panas [4]. Tangki penyimpanan digunakan untuk menyimpan air setelah dipanaskan agar panasnya bertahan lama.

Ada tiga tipe panel kolektor yang paling banyak diaplikasikan yaitu kolektor tipe datar, kolektor dengan sistem penyimpanan terintegrasi dan kolektor berbentuk pipa [5]. Panel kolektor tipe datar dapat menggunakan bahan-bahan yang bermassa ringan dan sederhana dengan absorber panas berlapis hitam (gelas atau polimer) sehingga dapat menghasilkan efisiensi penyerapan energi surya sebesar $60 \%$.

Pemanas air panel surya merupakan aplikasi profit pemanfaatan panel surya. Sistem sederhana pemindah panas dengan kolektor berbentuk piring datar atau pipa dipasang secara bertingkat-tingkat dan horizontal pada atap bangunan dapat menghasilkan suhu pemanasan $100-160^{\circ} \mathrm{C}$ sedangkan kolektor konsentrasi (Fresnel, bak parabola, menara dan oven) dapat mencapai suhu pemanasan hingga $250^{\circ} \mathrm{C}$ [6]. Penelitian yang telah disajikan Ogie dkk. [7] temperatur maksimum dan temperatur kolektor yang mampu dicapai oleh pemanas air surya dengan kolektor bertipe datar adalah $55^{\circ} \mathrm{C}$ dan $51^{\circ} \mathrm{C}$ pada $1480 \mathrm{~W} / \mathrm{m}^{2}$.

Tujuan penelitian ini adalah merancang dan menguji Pemanas Air Surya Tipe Datar yang dapat digunakan sebagai sumber panas untuk produksi energi terbarukan sebagai contoh biodiesel dan bioetanol. Pemanas air surya dibuat menggunakan material yang ringan dan lebih ekonomis. Selain itu pula pemanas air dirancang sederhana sehingga lebih mudah untuk dioperasikan. Indikator yang diuji adalah temperatur tangki penyimpanan air dan intensitas cahaya surya. Aplikasi dari teknologi ini diharapkan dapat meningkatkan kemandirian masyarakat dalam pemenuhan kebutuhan energi, khususnya daerah pedalaman dan perbatasan yang sering mengalami krisis bahan bakar dan belum teraliri listrik. Selain itu pula, pemanfaatan teknologi ini dapat mengurangi ketergantungan masyarakat terhadap kebutuhan bahan bakar fosil.

\section{METODELOGI PENELITIAN}

\subsection{Bahan dan Alat}

Pemanas air surya yang dirancang memiliki kolektor surya berbentuk datar. Kolektor surya berbentuk datar dengan penutup kaca dalam kotak isolator bewarna hitam. Berikut rangkaian pemanas air surya yang dirancang, dapat di lihat pada gambar 1.

Penggunaan bahan dan rangkaian yang tepat akan meminimalisir kehilangan panas pada kolektor surya [8]. Data spesifikasi material pemanas air surya yang dirancang disajikan pada Tabel 1. 


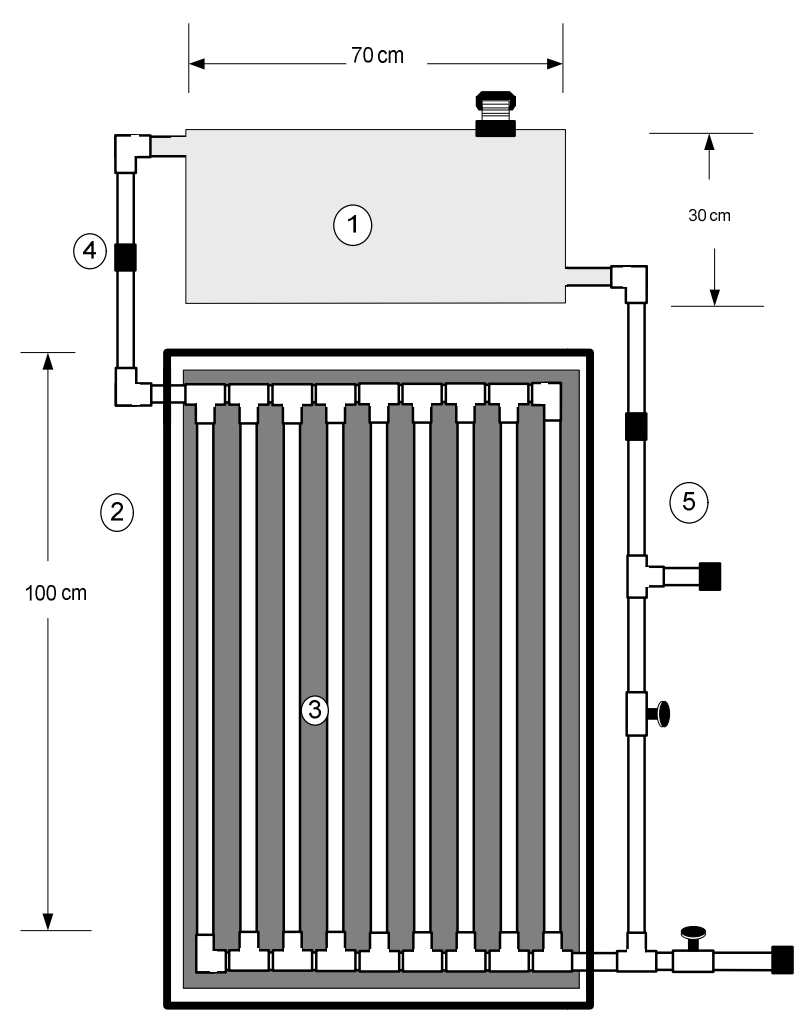

Gambar 1. Rancangan pemanas air surya: (1) Tangki penyimpanan; (2) Kolektor surya; (3) Pipa perpindahan panas; (4) Pipa aliran atas; (6) Pipa aliran bawah

Tabel 1. Spesifikasi pemanas air surya

\begin{tabular}{lll}
\hline Bagan & Bahan & $\begin{array}{l}\text { Ukuran } \\
(\mathbf{p x l ) c m}\end{array}$ \\
\hline $\begin{array}{l}\text { Tangki } \\
\text { penyimpan air }\end{array}$ & $\begin{array}{l}\text { Tabung: Stainlees } \\
\text { steel } \\
\text { Isolator Polistiren }\end{array}$ & $70 \times 30$ \\
\hline Pipa kolektor & Stainless steel & $70 \times 2,5$ \\
\hline Penutup & Kaca akrilik & $70 \times 100$ \\
\hline Absorber & Polistiren hitam & $70 \times 100$ \\
\hline Pipa aliran & Stainless steel & $150 \times 2,5$ \\
\hline
\end{tabular}

\subsection{Prosedur}

Tahapan penelitian terdiri dari pembuatan pemanas air surya tipe datar dan uji coba pemanas air surya. Uji coba pemanas air surya dilakukan selama 3 hari dengan waktu pemanasan selama 6 jam. Indikator yang diukur adalah temperatur tangki dan intensitas cahaya surya.

\section{HASIL DAN PEMBAHASAN}

\subsection{Pemanas air surya}

Pemanas air dirancang mengguanakn bahan yang lebih ekonomis dan dapat dioeparasikan dengan mudah, sehingga dapat menekan biaya produksi alat dan Pemanas air surya yang dirancang terdiri dari surya kolektor dan tangki penyimpanan air. Surya kolektor terdiri atas beberapa bagian yaitu:
1. Pipa perpindahan panas dibuat dari bahan stainless steel sehingga dapat mengurangi laju korosi dan panas dapat diserap dengan baik oleh pipa.

2. Penutup luar dibuat dari bahan kaca akrilik, sehingga dapat mengoptimlakan energi surya yang diserap.

3. Lapisan hitam dibuat dari bahan polistiren yang dicat hitam dimaksudkan untuk meningkatan penyerapan energi panas oleh air dalam pipa pada pemans air surya (emitivitas lapisan hitam $=1$ ).

Tangki penyimpanan air dibuat dari bahan stainless steel dan lapisan isolator yang terdiri dari busa dan alumunium foil. Lapisan isolator diharapkan dapat meredam panas air sehingga mengurangi energi panas yang hilang ke lingkungan. Air dalam pipa menyerap panas dari surya sehingga temperatur air naik. Perbedaan densitas antara air panas dan air dingin, sehingga air panas mengalir ke atas dan air dingin mengalir ke bawah. Hal ini berkelanjutan sehingga membentuk sirkulasi. Sehingga tanpa bantuan tenaga pompa air dapat mengalir.

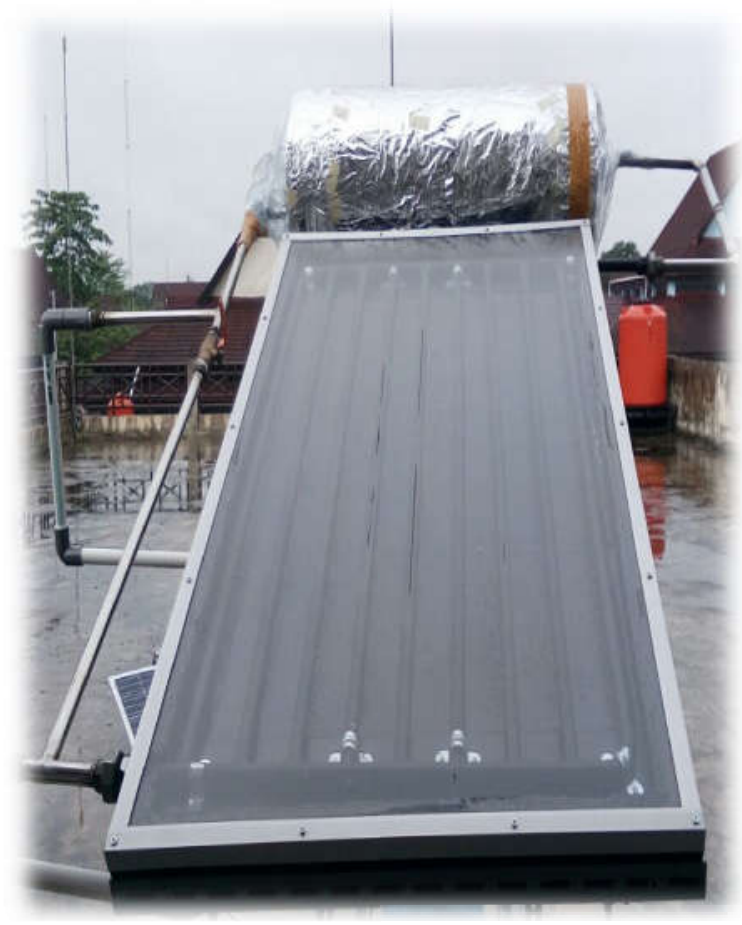

Gambar 2. Sistem Panas Air Surya hasil rancangan

Radiasi yang dipancarkan permukaan pemanas merupakan radiasi dengan gelombang yang panjang. Kaca memiliki sifat tak tembus dengan cahaya panas pada radiasi gelombang panjang sehingga panas dapat masuk. Radiasi surya masuk ke kolektor melalui penutup transparan (kaca akrilik) dan mencapai absorber dimana radiasi diubah menjadi bentuk energi panas. Bahan dengan kondukstivitas panas yang baik dibutuhkan untuk memindahkan panas yang terkumpul ke pipa kolektor untuk dihantarkan keair. Absorber berupa polistiren ringan yang dicat warna hitam berfungsi untuk mengurangi kehilangan energi radiasi. Pelapisan warna hitam pada permukaan absorber dapat mengurangi kehilangan energi radiasi sebesar 4\% hingga $7 \%$ [9]. 


\subsection{Uji coba pemanas air surya}

Air dalam pipa menyerap panas dari surya sehingga temperatur air naik. Perbedaan densitas antara air panas dan air dingin, sehingga air panas mengalir ke atas dan air dingin mengalir ke bawah. Hal ini berkelanjutan sehingga membentuk sirkulasi.

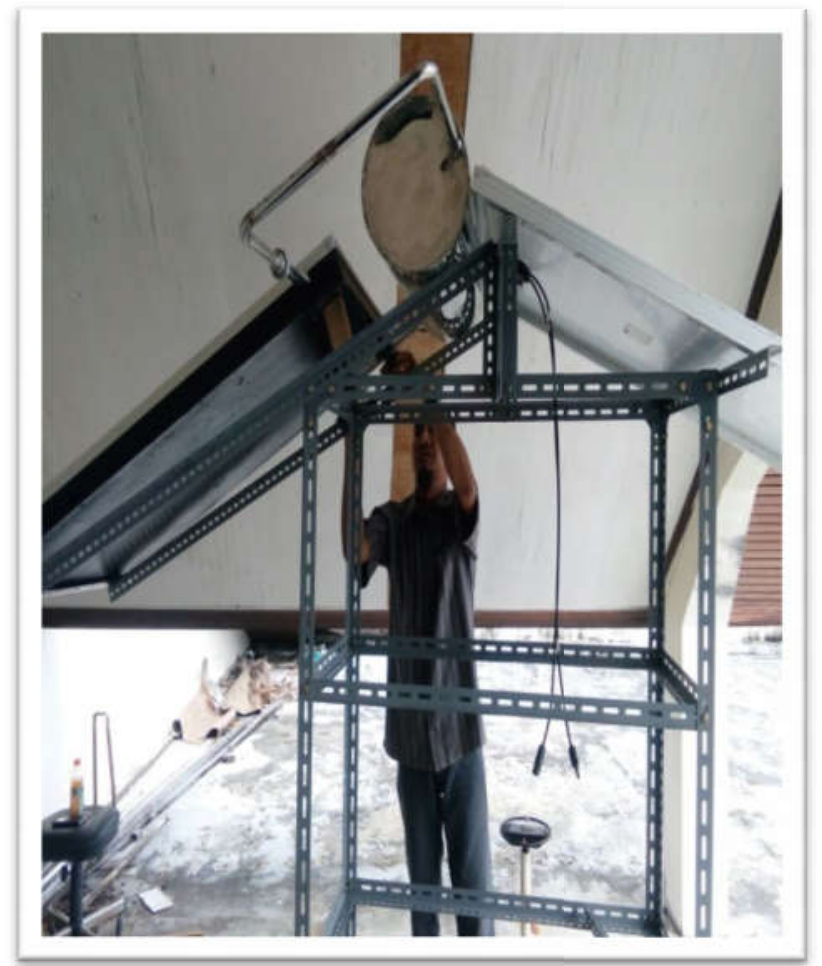

Gambar 3. Proses pengambilan data pemanas air surya

Uji coba dilaksanakan pada bulan terjadinya fenomena titik kulminasi surya di Kota Pontianak. Kulminasi adalah fenomena dimana posisi surya tepat berada di garis khatulistiwa. Hal ini juga dapat meningkatkan intensitas cahaya yang diserap oleh pemanas air surya. Selain itu pula untuk meningkatkan temperatur air panas maka di reaktor ditambahkan elemen pemanas. Elemen pemanas ini dijalankan menggunkan energi listrik searah dari panel surya.

Beberapa hal yang dapat mempengaruhi tidak optimumnya temperatur air yang diperoleh adalah:

1. Sinar surya yang menyinari bumi tidak stabil selama waktu percobaan.

2. Panas yang diserap sebagian hilang ke lingkungan.

Pemanas air surya ditempatkan pada atap bangunan supaya sinar surya dapat diserap secara optimal. Berdasarkan hasil pengamatan yang dilkaukan selama 3 hari, setiap hari mulai pukul 9.00 hingga 13.00 diperoleh data yang disajikan pada Tabel 2 .
Tabel 2. Data hasil uji pemanas air surya

\begin{tabular}{|c|c|c|c|}
\hline $\begin{array}{l}\text { Hari } \\
\text { ke- }\end{array}$ & Waktu & $\begin{array}{c}\text { Temperatur air } \\
\left({ }^{\circ} \mathrm{C}\right)\end{array}$ & $\begin{array}{c}\text { Intensitas Cahaya } \\
\text { (lux) }\end{array}$ \\
\hline \multirow{5}{*}{ I } & 09.00 & 39,60 & 732,00 \\
\hline & 10.00 & 48,40 & 1118,00 \\
\hline & 11.00 & 53,30 & 1193,00 \\
\hline & 12.00 & 54,40 & 1172,00 \\
\hline & 13.00 & 53,60 & 1426,00 \\
\hline \multirow{5}{*}{ II } & 09.00 & 38,80 & 782,00 \\
\hline & 10.00 & 46,00 & 971,00 \\
\hline & 11.00 & 52,00 & 1164,00 \\
\hline & 12.0 & 54,20 & 1122,00 \\
\hline & 13.00 & 53,10 & 162,30 \\
\hline \multirow{5}{*}{ III } & 09.00 & 31,60 & 744,00 \\
\hline & 10.00 & 42,30 & 1062,00 \\
\hline & 11.00 & 46,10 & 1156,00 \\
\hline & 12.00 & 48,20 & 1029,00 \\
\hline & 13.00 & 52,60 & 1090,00 \\
\hline
\end{tabular}

Temperatur air yang lebih tinggi dapat dihasilkan dengan meningkatkan konsentrasi radiasi cahaya ke permukaan absorber [10]. Kolektor surya harus terpasang dengan sudut kemiringan yang tepat menghadap sinar surya. Pada pemanas air yang dirancang sudut kemiringan kolektor surya sebesar $30^{\circ}$.

\section{KESIMPULAN}

Pemanas air surya tipe datar yang telah dirancang memiliki dua bagian yaitu kolektor panas dan tangki penampungan air panas. Pemanas air surya menggunakan bahan yang bermassa ringan dan dirangkai secara sederhana sehingga mudah untuk dioperasikan. Hasil uji coba pemanas air surya diperoleh temperatur maksimum air yaitu $53{ }^{\circ} \mathrm{C}$ pada intensitas cahaya 1426 lux.

\section{UCAPAN TERIMA KASIH}

Pendana penelitian teknologi terapan dari Kementerian Riset Teknologi dan Pendidikan Tinggi.

\section{DAFTAR PUSTAKA}

[1] H. Bradke, C. Doetsch, H. Huhn, dkk., Researching: energi, brochure, Aliance of Scientific Organizations, Germany, 2011.

[2] SSI, "Pembangkit Listrik Tenaga Surya: Solar Surya Indonesia", Ditjen Listrik dan Pengembangan Energi, Jakarta, 2015. 
[3] Verma, Abhishek, Kumar dan Vishal, "Solar Water Heating System", IJRAME. Vol 3 Issue 1, pp 53-63, 2015.

[4] Weiss W, "Solar Thermal, State of the art, Application Areas and Preview of Technology Development", IEA Solar Heating and Cooling Roadmap Workshop, 28-29 April, Paris. 2015

[5] Okafor dan Basil, "Thermo Siphon Solar Water Heater". IJET, vol.3 no.3, 2013.

[6] Gangane, S.D, Bhere, S.H, dkk, "Economical Solar Water Heater,” IOSR- JMCE, pp 68-71, 2017.

[7] Ogie dkk,“ Design and construction of Solar water heater based on the thermo siphon principle, JFREA, vol. 3. 2013.

[8] C. Homola, "Solar Domestic Hot Water Heating Systems Design, Installation and Maintenance', Solar Rating and Certification Corporation, 2014.

[9] C. Philibert, "Solar Energi Perspectives, Renewable Energi Technologies", French: International Energi Agency, 2014.

[10] Tarquini, Pietro, "Hydrogen and Fuels Production by Solar Thermochemical Cycle", Energy and Sustainable Economic Development, Itali, 2011. 